\title{
Extraluminal compression of an aortic graft simulating recoarctation
}

\author{
AUDREY STERN, BRUCE P MINDICH, * JONATHAN L HALPERIN \\ From the Cardiothoracic Center, Mount Sinai Medical Center, New York, NY, USA
}

SUMMARY Restenosis rarely develops after surgical correction of coarctation of the aorta in adults. Late morbidity is usually related to residual hypertension or progressive aortic valve disease. patient in whom symptoms and signs of recurrent coarctation developed 19 years after initial graft repair is described. Dehiscence of the original silk suture line was found at operation. Extensive thrombus had produced graft compression. Milder hypertension persisted in the postoperatiue period despite relief of the aortic obstruction.

Late morbidity after repair of coarctation of the aorta in adulthood is usually caused by residual hypertension, development of coronary atherosclerosis, aneurysm formation, stroke, aortic valve disease, or congestive heart failure. ${ }^{1-3}$ Recoarctation rarely develops when the initial operation is performed in adulthood, but stenosis may develop when the enlarging aorta outgrows a synthetic graft inserted earlier in life. We encountered a case in which apparent recoarctation developed as a result of dehiscence of the original suture line 19 years after initial repair. Extensive thrombus formation resulted in graft compression.

\section{Case report}

A 38 year old white woman presented with hypertension and claudication in the legs 19 years after surgery for repair of coarctation of the aorta. She had presented initially with similar findings, and angiography had identified a juxtaductal aortic coarctation beyond the left subclavian artery with preserved distal flow and associated ductus arteriosus. During the original operation the ductus arteriosus was ligated, a long coarctation was resected, and a $14 \mathrm{~mm}$ Dacron

Present address: *St Luke's-Roosevelt Medical Center, Department of Cardiothoracic Surgery, Amsterdam Avenue and 114th Street, New York, New York 10025.

Requests for reprints to Dr Jonathan $L$ Halperin, Division of Cardiology, Mount Sinai Medical Center, Fifth Avenue at 100th Street, New York, NY 10029, USA. graft was inserted with a silk suture. The patient dite well in the postoperative period; blood pressuge became normal, claudication remitted, and sme enjoyed an active lifestyle and completed two full term pregnancies without difficulty. At 38 sfe experienced fatigue and dyspnoea and claudication of the calves, thighs, hips, and buttocks on bogh sides. She was admitted to hospital with congestive heart failure and the blood pressure was the $230 / 112 \mathrm{~mm} \mathrm{Hg}$. Congestion and hypertensiö responded to administration of diuretic and vas 8 dilator medications. At readmission her medications included metolazone (10 mg daily) and clonidire ( $0.1 \mathrm{mg}$ three times a day); she had stopped using aspirin nine months before.

Physical examination found the patient in no distress at rest and well developed with a full, but not webbed, neck. The supine blood pressure wos $168 / 90 \mathrm{~mm} \mathrm{Hg}$ in the left arm and $180 / 95$ in the right. The heart rate was 60 beats $/ \mathrm{min}$ with occs sional extrasystoles. The lung fields were clear. A systolic murmur was heard over the left chest postes riorly and radiated toward the midline and left renfal fossa. Anteriorly, the murmur was heard over the left pectoral and manubrial areas. There was no jugular venous distension and the carotid arterial pulse wos normal. An apical mid-systolic murmur and click were heard but no diastolic murmurs were heard. Examination of the abdomen showed no organ enlargement. The femoral pulse and more disfill pulses of the legs were delayed and markedly diminished in volume. Systolic pressure at the ankles, registered with the Doppler ultrasound device, wo्gिs 
$75 \mathrm{~mm} \mathrm{Hg}$ at rest while supine and $70 \mathrm{~mm} \mathrm{Hg}$ after exercise.

The electrocardiogram displayed normal sinus rhythm and large voltages characteristic of left ventricular hypertrophy. Chest $x$ ray showed normal cardiac dimensions and pulmonary vasculature but there was evidence of mild rib notching. Cross sectional echocardiography showed normal chamber

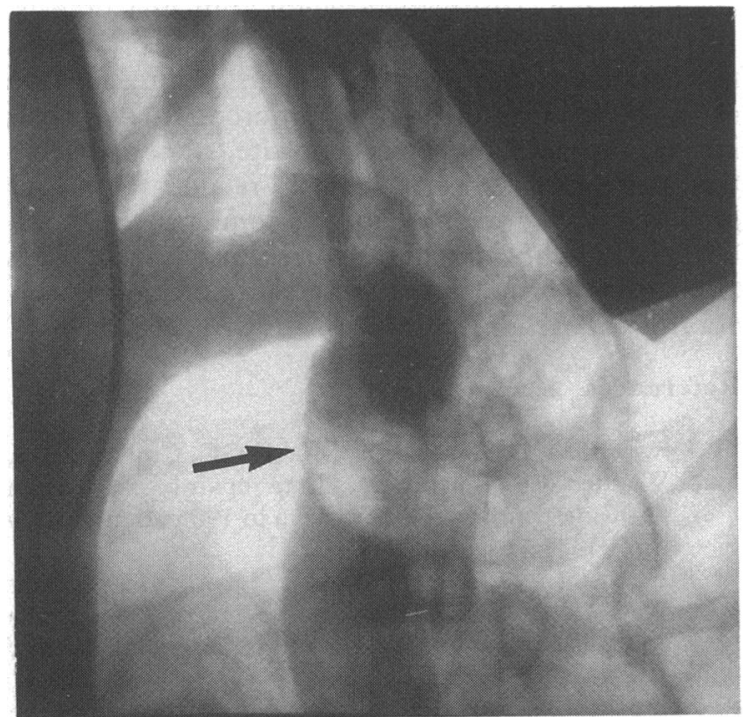

Fig 1 Aortic angiogram in the left anterior oblique projection showing severe eccentric narrowing beyond the origin of the left subclavian artery as well as a large filling defect at the site of narrowing (arrow).

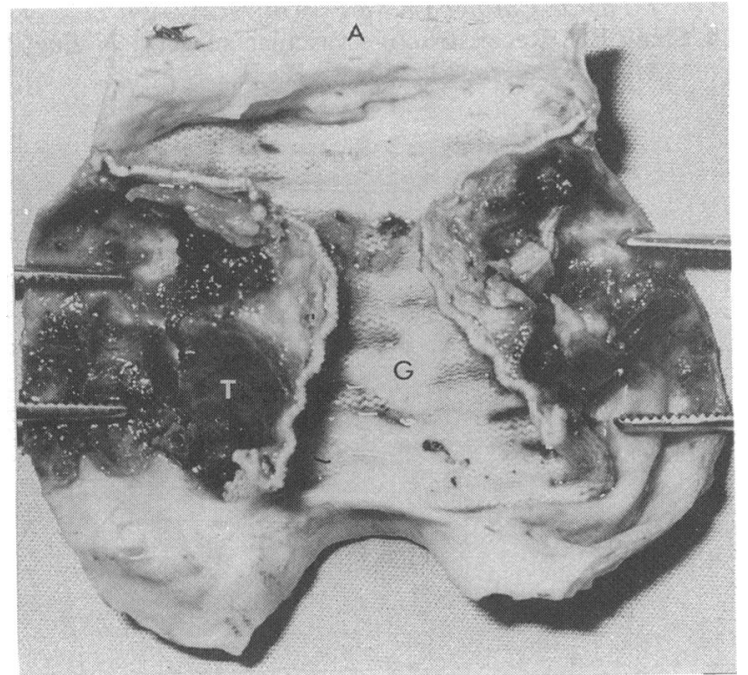

Fig 2 Excised segment of aorta $(A)$ and graft ( $G)$ showing extensive thrombus $(T)$ compressing the lumen of the graft. dimensions. The aortic valve was not well visualised; however, intracardiac Doppler analysis demonstrated aortic insufficiency.

\section{CARDIAC CATHETERISATION AND ANGIOGRAPHY}

Right and left heart catheterisation was performed from the right antecubital approach. The pulmonary artery pressure was $30 / 14 \mathrm{~mm} \mathrm{Hg}$ and the left ventricular pressure was $240 / 16 \mathrm{~mm} \mathrm{Hg}$ at rest. The cardiac index measured by the thermodilution technique was $31 / \mathrm{min} / \mathrm{m}^{2}$. Angiography showed severe eccentric narrowing of the descending aorta just distal to the origin of the left subclavian artery and a large filling defect at the site of narrowing (fig 1). Three aortic sinuses were identified and aortic insufficiency (grade $2+$ ) was demonstrated.

\section{SURGICAL FINDINGS AND POSTOPERATIVE COURSE}

Left thoracotomy was performed through the original incision site at the level of the previously resected fifth rib. The area of original coarctation repair was identified and appeared well healed without evidence of infection. An aneurysmal dilatation approximately $3.5 \mathrm{~cm}$ in diameter was found in the region of the proximal anastomosis. The proximal suture line appeared to have dehisced along half its circumference. Dissection around the graft and extensive thrombus formation had compressed the graft to less than $10 \%$ of its potential diameter (fig 2 ). The distal suture line was intact and there was slight neointimal hyperplasia. The graft was excised and replaced with a new $18 \mathrm{~mm}$ preclotted woven Dacron prosthesis and a Prolene suture was used to fashion the end to end anastomosis. Postoperatively, hypertension developed and treatment with intravenous nitroprusside, propranolol, and methyldopa was needed. Eventually an oral regimen of labetalol and diuretic was sufficient to maintain pressure in the normal range and the patient was discharged from the hospital on the eighth postoperative day after an otherwise uneventful recovery. A month after operation she was symptom free, with no dyspnoea or claudication. Blood pressure was well controlled, no murmurs were heard over the thorax, and pulses throughout the legs were strong.

\section{Discussion}

Repair of aortic coarctation by synthetic graft replacement has become increasingly common since its introduction in 1960, and the technique was used in approximately $65 \%$ of patients in a series reported by DeBakey's group. ${ }^{1}$ Features of coarctation calling for graft interposition include $(a)$ involvement of a 
long aortic segment in the coarctation, (b) a small calibre proximal aortic segment, $(c)$ the need for resection of an associated aneurysm, $(d)$ inelasticity of the aorta in older patients, and $(e)$ technical intraoperative complications. In all forms of surgery for relief of coarctation, late morbidity and mortality are usually associated with residual hypertension and take the form of myocardial infarction, congestive heart failure, stroke, and aneurysm formation. Important aortic valve disease may also develop but complications directly related to the graft anastomotic suture line are unusual.

Pennington et al reported an experience of the Massachusetts General Hospital with surgical treatment of aortic coarctation (1947-76). ${ }^{4}$ Fifty nine $(36 \%)$ of 164 patients underwent resection and interposition grafting. Fifty three per cent of patients aged $>10$ years and $66 \%$ of patients aged $>40$ years had interposition grafts. Only one of the late deaths was related to rupture of a pseudoaneurysm at a silk suture line. This was found 17 years after operation. There were no cases of restenosis in patients with synthetic grafts or even of relative stenosis caused by outgrowing the graft.

Of the 190 patients who underwent surgical correction of coarctation of the descending aorta at Baylor, late postoperative mortality occurred in 18 cases. ${ }^{1}$ Two thirds of these deaths were attributed to myocardial infarction or heart failure. Fatal rupture of aortic aneurysm occurred in two cases. Late morbidity developed in 14 patients: recurrent coarctation in three, true aneurysm in four, and pseudoaneurysm in one; six patients required aortic valve replacement. Aneurysms generally developed in patients with longstanding hypertension. The data provided mean that we cannot tell which patients were treated with synthetic grafts and which by primary anastomosis, but the rather low rate $\stackrel{\widetilde{O}}{\text { of }}$ recurrent stenosis was ascribed to the high proportion of cases managed with grafts.

Although resection and primary end to end anastomosis is the procedure of choice for repair off coarctation of the aorta, many patients, especial those undergoing late repair, require interposition of a synthetic graft. After reports of suture line failures with pseudoaneurysm formation ${ }^{5}$ silk has been abandoned as a suture material for graft anastomosis. In patients presenting with signs and symptoms $\overrightarrow{\text { of }}$ recoarctation long after initial repair by interposition of a synthetic graft, the differential diagnos includes coarctation at a second site, stenosis within the graft, or functional stenosis related to further growth of the aorta. Though less common, the possija bility of a significant anastomotic complication, such as occurred in our patient, warrants prompt eval오 ation if catastrophic rupture is to be avoided.

\section{References}

1 Lawrie GM, DeBakey ME, Morris GC, Crawford ES Wagner WF, Glaeser DH. Late repair of coarctatio of the descending thoracic aorta in 190 patients. Arch Surg 1981;116:1557-60.

2 Liberthson RR, Pennington DG, Jacob ML, Dagge WM. Coarctation of the aorta: review of 234 patients and clarification of management issues. $A m \mathcal{F}$ Card 1979;43:835-9.

3 Schuster SR, Gross RE. Surgery for coarctation of the aorta: review of 500 cases. $\mathcal{F}$ Thorac Cardiovasc Sug 1962;43:54-70.

4 Pennington DG, Liberthson RR, Jacobs M, Scully 争, Goldblatt A, Daggett WM. Clinical review of experience with surgical repair of coarctation of the aor f Thorac Cardiovasc Surg 1979;77:217-29.

5 Shaw RS. Reconstructive vascular surgery. $N$ Engl 7 f Med 1962;266:339-46. 